\title{
ANÁLISE DE CAMPANHAS TELEVISIVAS SOBRE HIV/AIDS: INTERFACES ENTRE BRASIL E ANGOLA
}

\author{
ANALYSIS OF TELEVISION CAMPAIGNS ON HIV/AIDS: \\ INTERFACES BETWEEN BRAZIL AND ANGOLA
}

\section{ANÁLISIS DE CAMPAÑAS TELEVISIVAS SOBRE VIH/SIDA: INTERFACES ENTRE BRASIL Y ANGOLA}

\author{
Isabelly Gomes de Oliveira ${ }^{1}$ \\ Lydia Vieira Freitas dos Santos ${ }^{2}$ \\ Antônio Uelton de Araújo da Silva ${ }^{3}$ \\ Márcio Flávio Moura de Araújo ${ }^{4}$ \\ Hévila Ferreira Gomes Medeiros Braga \\ Emanuella Silva Joventino Melo ${ }^{6}$
}

Como citar este artigo: Oliveira IG, Santos LVF, Silva AUA, Araújo MFM, Braga HFGM, Melo ESJ. Análise de campanhas televisivas sobre HIV/AIDS: interfaces entre Brasil e Angola. Rev baiana enferm. 2021;35:e38280.

\begin{abstract}
Objetivo: analisar as campanhas publicitárias do Brasil e de Angola acerca do HIV/Aids e refletir sobre os aspectos socioculturais relacionados à doença que possuem influência direta na sua concepção pelo ser humano. Método: estudo descritivo, exploratório e de caráter qualitativo. A busca do material audiovisual foi realizada no sítio de compartilhamento de vídeo YouTube. Os dados foram analisados com base na análise de conteúdo de Bardin. Emergiram quatro categorias temáticas: "Métodos de proteção abordados nas propagandas"; "Protagonistas das propagandas"; "Apelos comportamentais incorporados"; "Aspectos culturais abordados". Resultados: os diferentes contextos culturais influenciam diretamente nas companhas publicitárias, pois, enquanto no Brasil as ações são voltadas para o uso do preservativo no período carnavalesco, em Angola o foco engloba as relações extraconjugais e o compartilhamento de fômites. Considerações finais: campanhas publicitárias são importantes meios de transformação social, podendo promover melhorias na mudança de comportamento dos indivíduos e na prevenção de doenças e agravos.
\end{abstract}

Descritores: Mídia Audiovisual. Síndrome de Imunodeficiência Adquirida. Brasil. Angola.

Objective: to analyze the advertising campaigns of Brazil and Angola on HIV/Aids and to reflect on socio-cultural aspects related to this disease that has direct influence on its conception by human beings. Method: a descriptive and exploratory study, of a qualitative nature. The search for the audiovisual material was carried out on the YouTube video-sharing platform. The data were analyzed based on Bardin's content analysis. Four thematic categories emerged: "Protection methods addressed in the advertisements"; "Protagonists of the advertisements"; "Embedded behavioral appeals"; "Cultural aspects addressed". Results: the different cultural contexts have a direct influence on the advertising campaigns, for while in Brazil the actions are aimed at the use of condoms in the carnival period, in

\footnotetext{
Enfermeira. Mestre em Enfermagem. Residente em Enfermagem Obstétrica na Universidade Federal do Ceará. Maternidade Escola Assis Chateaubriand. Fortaleza, Ceará, Brasil. isa_belly_oliveira@hotmail.com. http://orcid.org/0000-0002-0022-0981.

Enfermeira. Doutora em Enfermagem. Professora da Universidade da Integração Internacional da Lusofonia Afro-Brasileira. Redenção, Ceará, Brasil. http://orcid. org/0000-0003-4277-7486.

Enfermeiro. Mestre em Enfermagem. Enfermeiro da Unidade de Pronto Atendimento Itaperi. Fortaleza, Ceará, Brasil. http://orcid.org/0000-0002-7670-7630.

Enfermeiro. Doutor em Enfermagem. Fundação Oswaldo Cruz. Eusébio, Ceará, Brasil. http://orcid.org/0000-000 I-8832-8323.

Acadêmica em Enfermagem. Universidade da Integração Internacional da Lusofonia Afro-Brasileira. Redenção, Ceará, Brasil. http://orcid.org/0000-0003-4I88-2882.

Enfermeira. Doutora em Enfermagem. Professora da Universidade da Integração Internacional da Lusofonia Afro-Brasileira. Redenção, Ceará, Brasil. http://orcid. org/0000-000 I-9786-5059.
} 
Angola the focus covers extramarital relations and fomite sharing. Final considerations: advertisement campaigns are important means of social transformation, and they can promote improvements in behavior changes of the individuals in the prevention of health problems and diseases.

Descriptors: Audiovisual Media. Acquired Immunodeficiency Syndrome. Brazil. Angola.

Objetivo: analizar las campañas publicitarias sobre el VIH/SIDA realizadas en Brasil y en Angola y reflexionar sobre los aspectos socioculturales relacionados con la enfermedad que ejercen una influencia directa sobre su concepción por parte del ser humano. Método: estudio descriptivo, exploratorio y de carácter cualitativo. La búsqueda del material audiovisual se realizó en el sitio de videos compartidos YouTube. Los datos se analizaron sobre la base del análisis de contenido de Bardin. Surgieron cuatro categorias temáticas: "Métodos de protección abordados en las propagandas"; "Protagonistas de las propagandas"; "Recursos conductuales incorporados"; "Aspectos culturales abordados". Resultados: los diferentes contextos culturales ejercen una influencia directa sobre las compañas publicitarias, puesto que, mientras que en Brasil las acciones están dirigidas al uso del preservativo durante el período de Carnaval, en Angola la campaña se enfoca en las relaciones extra-matrimoniales y en el uso compartido de fómites. Consideraciones finales: las campañas publicitarias son importantes medios de transformación social, que pueden promover mejoras en el cambio conductual de los individuos y en la prevención de enfermedades y problemas de salud.

Descriptores: Medios Audiovisuales. Sindrome de Inmunodeficiencia Adquirida. Brasil. Angola.

\section{Introdução}

A Síndrome da Imunodeficiência Adquirida (Aids ou Sida) configura-se como uma patologia que atinge o sistema imunológico. É causada pelo vírus da imunodeficiência humana (HIV ou VIH), que tem a capacidade de invadir as células de defesa (linfócitos T CD4+) e replicar seu RNA, multiplicando-se e adentrando em outras células $^{(1)}$. Com o sistema de defesa debilitado, o indivíduo acometido por esta doença torna-se mais suscetível a contrair infecções oportunistas, podendo chegar ao óbito.

Até o final de 2018, dados da Organização das Nações Unidas (ONU) indicam que 37,9 milhões de pessoas conviviam com o HIV no mundo $^{(2)}$. O continente africano é um dos mais afetados pela epidemia de HIV/Aids, sobretudo os países lusófonos, como Angola, Guiné-Bissau e Moçambique. Dados epidemiológicos sobre o HIV no Brasil revelam que, ao longo dos anos, o número de pessoas atingidas pelo vírus continua aumentando. Estima-se que havia aproximadamente 900 mil pessoas com HIV no país em 2018, das quais $44 \%$ não realizavam o tratamento com antirretrovirais ${ }^{(3)}$.

A maior parte das infecções por HIV dá-se por meio das mucosas genital ou retal durante relações sexuais desprotegidas ${ }^{(4)}$. Pelo fato de ainda não haver cura, o foco encontra-se na prevenção primária, por meio da adoção de práticas sexuais seguras, que são disseminadas e reforçadas junto à população por meio de ações educativas e campanhas de saúde ${ }^{(5)}$.

No cenário midiático, as propagandas televisivas possuem grande destaque na formação de ideias e opiniões, pois configuram-se como um meio de comunicação com alto potencial de influência sobre as atitudes dos indivíduos, podendo ocorrer o armazenamento das informações repassadas na memória com maior facilidade $^{(6)}$. No Brasil, tornou-se habitual o uso desse tipo de mídia para a prevenção da transmissão do HIV no período do carnaval, devido ao aumento das relações sexuais, muitas vezes desprotegidas e com mais de um parceiro, potencializando as chances de contaminação tanto pelo HIV como por outras Infecções Sexualmente Transmissíveis (IST).

As campanhas publicitárias enquadram-se no campo do marketing social, no qual diversas questões emergem, desde o uso de preservativo, incentivo ao diagnóstico e tratamento precoces, importância de realizar o teste, até as representações sobre os sujeitos, sexualidade e combate ao preconceito ${ }^{(7)}$. Desse modo, os meios 
publicitários tornam-se de suma relevância para a mudança de paradigmas e de imaginário social da doença.

O Dia Mundial da Luta contra a Aids tornou-se uma oportunidade eficaz para a divulgação dessas campanhas. Nesse ínterim, diversas estratégias de comunicação são adotadas com o intuito de informar a população sobre medidas preventivas do HIV/Aids ${ }^{(8)}$. Ademais, a categoria vídeo serve como importante ferramenta de informação dirigida, podendo ser utilizada de diferentes formas para alcançar pessoas dos mais diversos níveis sociais e educacionais.

Diante do contexto apresentado e sendo a Aids um problema de cunho global, atingindo notadamente as populações do Brasil e de Angola, na África, surgiu a necessidade de compreender como a doença vem sendo abordada nas propagandas televisivas, tendo em vista $\mathrm{O}$ alto teor de disseminação que possuem na coletividade.

Desta forma, este estudo tem como objetivos analisar as campanhas publicitárias do Brasil e de Angola e refletir sobre os aspectos socioculturais relacionados à doença que possuem influência direta na sua concepção pelo ser humano.

\section{Método}

Trata-se de um estudo descritivo, exploratório e de caráter qualitativo que assume por propósito analisar, interpretar e conhecer semelhanças e diferenças entre duas propagandas institucionais sobre HIV/Aids veiculadas nas mídias televisivas do Brasil e de Angola, identificando pontos relevantes nas estratégias e nos públicos aos quais foram destinadas.

A concepção deste artigo surgiu com base na disciplina Métodos Qualitativos do Mestrado Acadêmico em Enfermagem da Universidade da Integração Internacional da Lusofonia Afro-Brasileira (Unilab), que tem por missão promover a integralização entre os países de língua portuguesa.

É importante ressaltar que ambos os países objetos deste estudo fazem parte da Comunidade dos Países de Língua Portuguesa (CPLP) e estão ligados pela cooperação Sul-Sul, que visa formas de apoio ao desenvolvimento, fortalecimento de laços políticos, econômicos e culturais e compartilhamento de ferramentas tecnológicas e educacionais ${ }^{(9)}$.

Para seleção do material audiovisual, foi realizada inicialmente uma busca em sites governamentais e no sítio de compartilhamento de vídeo YouTube. A escolha do referido site deve-se à sua grande difusão entre os usuários da internet, abrangendo uma infinidade de materiais de fácil acesso. Além disso, no Brasil, o YouTube passou a ser, em 2019, a rede social mais utilizada, com mais de 1 bilhão de usuários ativos e mais de 1 bilhão de horas de vídeos visualizados diariamente ${ }^{(10)}$.

A busca pelos vídeos foi realizada no período de maio a junho de 2017. Para a pesquisa, utilizaram-se as palavras-chave "SIDA" e "HIV", associando-as aos nomes dos oito países que compõem a CPLP: Angola, Brasil, Cabo Verde, Guiné-Bissau, Moçambique, Portugal, São Tomé e Príncipe e Timor Leste. Como critérios de inclusão: ser vídeo governamental no estilo propaganda, em língua portuguesa e com ano de publicação mais recente em cada país. Foram excluídos os materiais produzidos por outros tipos de instituições, além dos vídeos no estilo documentário e com duração superior a 60 segundos.

A análise de vídeo constitui-se em uma importante escolha metodológica, pois possibilita a compreensão de um fenômeno complexo que envolve vários elementos, tais como textos, imagens e som que auxiliam na transmissão de saberes e dinamizam o processo de promoção do conhecimento $^{(11)}$.

Com base nos critérios de inclusão e exclusão, permaneceram para análise o vídeo da campanha do Departamento de DST, Aids e Hepatites Virais do Ministério da Saúde do Brasil, de 2017, referente ao carnaval, intitulado "Use camisinha e viva essa grande festa", e o vídeo institucional de Angola referente ao ano de 2009, intitulado "Infidelidade".

Foi realizado download dos vídeos para serem analisados. A análise deu-se pela descrição 
das imagens e áudios, possibilitando discussão e reflexão dos pesquisadores. Para nortear essa etapa, foram elaboradas as seguintes categorias: métodos de proteção abordados nas propagandas; protagonistas das propagandas; apelos comportamentais incorporados; e aspectos culturais abordados.

Foram aplicados os conceitos da análise de conteúdo, que, enquanto método, é definida como um conjunto de técnicas de análise de comunicação, visando obter, por meio de procedimentos sistemáticos e objetivos de descrição do conteúdo das mensagens, indicadores que permitam a inferência de conhecimentos relativos às condições de produção e recepção dessas mensagens ${ }^{(12)}$.

\section{Resultados e Discussão}

A primeira propaganda analisada foi a campanha do Ministério da Saúde do Brasil de 2017, a qual apresenta o tema "Use camisinha e viva essa grande festa", fazendo alusão ao período do carnaval, época em que, tradicionalmente, as campanhas brasileiras ganham mais ênfase. Em 31 segundos, são apresentados dados acerca do número de pessoas infectadas pelo HIV no Brasil, tanto aquelas que possuem consciência de que são portadoras do vírus, mas não realizam o tratamento adequado, como aquelas que desconhecem sua condição. As imagens ao longo do vídeo demonstram o clima festivo do carnaval brasileiro, expondo brincantes, em ruas e praias, que incentivam o uso do preservativo masculino durante a folia.

A propaganda angolana de 2009, que aborda o tema "Infidelidade" e possui 60 segundos de extensão, tem seu início marcado pela mensagem "O risco de infecção por VIH nos atos do nosso dia-a-dia [sic] é real!". Nesse contexto são apresentadas situações cotidianas em que o HIV pode ser transmitido, como o compartilhamento de alicates para unhas, escovas de dentes e em relações sexuais desprotegidas, por pessoas que não realizam testes para diagnóstico da doença. Além disso, o comercial apresenta a doação de sangue como forma de descoberta da doença e foca na prevenção como única maneira de se proteger da Aids.

\section{Métodos de proteção abordados nas propagandas}

A propaganda brasileira possui ênfase no uso do preservativo masculino como forma de prevenção da infecção pelo HIV, enquanto o vídeo angolano aborda várias formas de prevenção, além da prática de relações sexuais com o uso da camisinha, como o não compartilhamento de objetos cortantes, exemplificado pelo alicate de unhas e de escovas de dentes.

Pode-se então perceber que diferentes práticas e abordagens acarretam o acometimento de pessoas pelo HIV e todas merecem especial atenção das campanhas preventivas e educativas.

Considerado um eficaz método de barreira na prevenção do HIV/Aids e na prevenção de gestações não planejadas, o preservativo masculino é extremamente difundido nas campanhas preventivas brasileiras. Apresenta ainda outras vantagens, como a ausência de efeitos sistêmicos e raras contraindicações para seu uso ${ }^{(13)}$.

Sabe-se que o preservativo feminino também é um método de barreira com as mesmas finalidades do condon masculino, portanto é de similar eficácia e, ao contrário do que muitos imaginam, não causa desconforto durante as relações sexuais ${ }^{(13)}$. Entretanto, o uso ainda é pouco observado devido à maior dificuldade no manuseio e também pela falta de informação sobre sua real eficácia. Apesar de ser ofertado gratuitamente pela atenção básica, a ausência de familiaridade das mulheres com esse preservativo acarreta efeitos insatisfatórios, podendo levar à utilização errônea e redução da eficácia do método ${ }^{(14)}$.

O uso compartilhado de objetos cortantes é um fator que aumenta as chances de o indivíduo contrair HIV, além de outras doenças infectocontagiosas. Apesar da pouca divulgação no Brasil, o compartilhamento de escovas de dentes, assim como de outros itens de higiene pessoal, também pode acarretar na transmissão da Hepatite $\mathrm{C}$ e do $\mathrm{HIV}^{(15)}$. Em contrapartida, a propaganda angolana evidencia a preocupação da 
prevenção da Aids não somente em uma época específica do ano, mas também nas atividades rotineiras do ser humano e em seus hábitos mais elementares de vida.

A sazonalidade das campanhas brasileiras acerca da prevenção das ISTS/Aids, sobretudo no período do carnaval, prejudica a consolidação de uma proposta informativa e educativa sobre as práticas sexuais ${ }^{(16)}$. Em vista disso, surge o questionamento do motivo de, no Brasil, a prevenção de uma infecção grave e sem cura ser exaltada em um período tão curto do ano como o carnaval, ainda que se saiba que, nessa época, o aumento da promiscuidade e das relações sexuais desprotegidas aumente. Assim, questiona-se: Por que não investir também na prevenção por meio de outras práticas que talvez possuam efeito igual ou maior quanto à prevenção no período carnavalesco? Já houve ações de saúde voltadas para os mitos e verdades sobre o contágio pelo HIV no Brasil, porém estas permanecem mais institucionalizadas e direcionadas ao âmbito da atenção básica, não dispondo de uma divulgação tão veemente quanto o uso da camisinha.

Pode-se inferir que negligenciar as demais formas de prevenção contra a Aids pode ser tão negativo quanto não se investir na promoção de informações de nenhum método de barreira, visto que o número de pessoas infectadas no Brasil mantém-se praticamente sem redução nos últimos anos.

\section{Protagonistas da propaganda}

Durante a exibição do vídeo brasileiro, aparecem pessoas de diferentes sexos, raças e gêneros, o que permite a comparação com o conceito equivocado, disseminado nas décadas anteriores, de que o HIV/Aids era contraído somente por homossexuais. A inserção de diversos personagens remete à ideia de que qualquer pessoa que tenha relações sexuais sem o uso do preservativo é passível de contaminação pelo vírus, independentemente de sua identidade de gênero, sexo, cor ou classe social.

A campanha publicitária de Angola é restrita ao círculo familiar e de amizades. Inicialmente, o vídeo aborda "O risco de infecção por HIV nos atos do nosso dia-a-dia [sic], é real!". Apresenta as personagens iniciais, ambas do sexo feminino, compartilhando objetos de uso pessoal (alicate e cortador de unhas), reforçando que elas nunca fizeram teste de HIV. Entretanto, devido a uma das mulheres ser soropositiva, transmite o vírus à outra que, sem saber, acaba por infectar sua irmã por meio de compartilhamento de escova de dentes; esta última infecta também seu namorado, por não utilizarem preservativo durante as relações sexuais. O ciclo de transmissão é extenso, chegando a infectar a chefe do namorado da personagem citada anteriormente e também seu marido, devido a relacionamentos extraconjugais.

Os meios de transmissão do HIV dão-se pelas mais variadas formas. Desta maneira, o vídeo angolano tem como foco alertar para as vias de transmissão, entretanto enfatiza mais as relações extraconjugais do que propriamente os métodos de prevenção. Nesse contexto, a concepção da homossexualidade não é abordada. Isso pode estar associado ao fato de ser forte o preconceito ainda instaurado nos países africanos, fruto de uma sociedade sexista, que preza pela distribuição de funções de acordo com o sexo, em que muitos afirmam que essa realidade não pertence à sua cultura e à sua nação.

Se, por um lado, não abordar casais homossexuais em uma propaganda contra HIV/Aids transmite uma impressão de inexistência do preconceito que se estabeleceu na sociedade, ao associar a doença como exclusiva desse grupo, por outro lado, pode conduzir à ideia de que a transmissão só ocorre em grupos heterossexuais que praticam a infidelidade. Desse modo, a inclusão de diversos personagens, no que concerne ao gênero, assim como ocorre na propaganda brasileira, representa a importância de conscientização de todos os indivíduos, independentemente de suas particularidades.

\section{Apelo comportamental abordado pelas propagandas}

O Ministério da Saúde do Brasil aborda a importância do uso do preservativo masculino 
durante as relações sexuais para prevenção da contaminação por HIV. Além disso, quando preciso, os testes de HIV podem ser realizados para fins diagnósticos.

Como já descrito, o apelo angolano engloba atitudes além da esfera das relações sexuais, indo até atos mais simples do cotidiano que têm a capacidade de aumentar as chances de proteção aos indivíduos contra o HIV.

O uso do preservativo é um assunto refletido no mundo desde que se teve a concepção do HIV como uma doença grave. Sua incorporação à rotina das pessoas já vem sendo difundida desde a adolescência, período quando costumam acontecer as primeiras relações sexuais. Entretanto, muitas vezes, sua utilização é dispensada devido à crença na invulnerabilidade, confiança estabelecida no relacionamento, recusa de um dos parceiros, uso de álcool e outras drogas ou pelo fato de não gostar ${ }^{(17)}$, afora o fato de que pessoas que mantêm relacionamentos estáveis apresentam maior dificuldade em manter o uso de preservativos ${ }^{(18)}$. Além disso, em um estudo sobre vulnerabilidade ao HIV/Aids entre universitários de diversas áreas, pôde-se perceber que, mesmo com o conhecimento elevado sobre a infecção e suas formas de transmissão, ainda havia baixa adesão ao uso de preservativos ${ }^{(19)}$.

Com base nesse conhecimento, emergem reflexões sobre como os comportamentos do ser humano podem mudar em suas relações com o outro, e se o descuido com a saúde ocorre em grupos sociais que possuem relativo conhecimento sobre as consequências do HIV, já que indivíduos que não possuem tal consciência estão ainda mais expostos a contrair a doença.

Os Testes Rápidos (TR) têm a possibilidade de ampliar o diagnóstico do HIV, uma vez que podem ser realizados em diversos ambientes, como na Atenção Primária, laboratórios e outros segmentos de saúde. Por utilizarem a mucosa oral, diminuem os riscos de contaminação do profissional de saúde que coleta, além de minimizar o tempo de espera do paciente, reduzindo as chances de não retornar à unidade para buscar o resultado ${ }^{(4)}$.
O estímulo da população para a realização frequente do exame tem o intuito de diagnosticar precocemente a doença, para dar início ao tratamento adequado que diminua a possibilidade de agravos à saúde, aumentando a expectativa de vida. Além disso, ao se ter um diagnóstico positivo de HIV, os profissionais de saúde podem, por meio da escuta ativa e das orientações ao paciente, evitar a transmissão do vírus para outras pessoas.

Mais do que esclarecer as pessoas com HIV sobre sua responsabilidade de interromper a cadeia de transmissão do vírus, os profissionais de saúde devem acolhê-las de forma a estimulá-las a realizar o tratamento adequado. Em Angola, por exemplo, muitas pessoas recusam-se a consumir os medicamentos, devido ao sentimento de negação que não desejam abrir mão ${ }^{(20)}$.

Por isso, deve-se orientá-las sobre como enfrentar o preconceito em torno da doença, pois o indivíduo portador do HIV pode viver em pleno convívio social, exercer atividades de trabalho e lazer, frequentar qualquer tipo de ambiente que lhe agrade e ser um exemplo de vida e de resiliência para a sociedade. Esta, por sua vez, deve estar preparada para quebrar paradigmas e acolher toda e qualquer pessoa, independentemente de sua condição de saúde. Isso pode acontecer também por meio do papel influenciador da mídia que, ao divulgar mitos sobre a transmissão do vírus, é capaz de empoderar os indivíduos, levando-os a refletir acerca do preconceito.

Os apelos comportamentais demandados pela sociedade angolana, embora mais simples, tangem ao ponto de hábitos socioculturais que devem ser revistos, como o compartilhamento de objetos pessoais. Por se tratar de um país recentemente declarado independente, diversos aspectos sociais emergem, como as condições financeiras das pessoas, fator que pode ser responsável pela necessidade de se dividir, por exemplo, uma escova de dentes. Entretanto, cabe ao Governo atentar para essas peculiaridades, a fim de reduzir o número de pessoas infectadas com o HIV, por meio da sensibilização e do fornecimento de materiais individualizados, 
tais como os de higiene. Essas campanhas podem ser levadas também às manicures e pessoas em geral que possuem o costume de utilizar o mesmo alicate de unhas.

No que remete às relações sexuais desprotegidas em Angola, pode-se perceber a influência de modelos poligâmicos. Nesses casos, ao se negligenciar o uso do preservativo, o ciclo de transmissão do HIV pode estender-se, acometendo mais e mais pessoas. Hábitos como esse devem ser desencorajados. Pelo fato de saber-se da dificuldade de se mudar a cultura de determinada sociedade, ações redutoras de danos, como o uso do preservativo, independentemente de os parceiros serem casados ou não, devem ser debatidas e levadas à população. Este problema não é intrínseco apenas a esse país ou somente aos países africanos, sendo o Brasil um exemplo do mesmo tipo de comportamento. Dessa forma, o empoderamento dos indivíduos mostra-se essencial, independentemente de qual cultura esses sejam adeptos.

\section{Aspectos culturais abordados}

Os aspectos culturais retratados nos vídeos denotam como a infecção pelo HIV é abordada em cada país. Nota-se que, no Brasil, todas as relações estabelecem-se na campanha publicitária, além de serem direcionadas para os métodos de proteção e prevenção, mais especificamente o uso do preservativo masculino. Essa preocupação fica evidenciada também na abertura do vídeo que, em forma de enredo de escola de samba, faz o seguinte chamado: "Olha a prevenção da Aids aí, gente!"

Por sua vez, em Angola, as noções de proteção contra a Aids são mais direcionadas para o não compartilhamento de objetos de uso pessoal, como o corta unhas e o alicate, e também a escova de dentes. Enfatiza ainda o fato de as duas personagens não terem realizado teste de HIV e a importância da fidelidade para a prevenção da Aids, conforme descrito no trecho "seja fiel e tenha um só parceiro sexual".

O não compartilhamento de objetos pessoais e de higiene pode ser exemplificado na passagem do vídeo em que é feita a seguinte orientação: "Não compartilhe escova de dentes". Apesar de o compartir com familiares a escova de dentes não ser a via mais comum de infecção, a transmissão também pode ocorrer. Esta é uma prática comum em Angola, principalmente entre famílias de baixa renda ${ }^{(21)}$.

Percebe-se, portanto, que a forma de enfrentamento da Aids ocorre de maneiras distintas nos dois países, e essas abordagens podem ser compreendidas por meio dos contextos políticos e sociais de cada um deles. Salienta-se que a guerra civil foi um fator que conteve a expansão da Aids/HIV em Angola, pois a movimentação ficou restrita a pequenos trechos territoriais ${ }^{(22)}$.

A comunicação social em Angola sobre HIV/Aids está cada vez mais reduzida e questões financeiras e de vontade política comprometem a realização de campanhas de prevenção ${ }^{(23)}$. Devido a isso, as formas de prevenção da campanha publicitária implementada pelo governo de Angola não contemplam o principal meio de infecção pelo HIV, que é pela relação sexual sem o uso do preservativo, considerado uma importante forma de prevenção da transmissão do $\mathrm{HIV}^{(24)}$.

Outra reflexão necessária fica por conta das questões pertinentes aos relacionamentos extraconjugais. Estas relações podem ser colocadas como principal foco, pois ainda é comum a poligamia em Angola, prática que diminui o valor social da mulher, atribui-lhe apenas a responsabilidade de ser mãe e esposa e impõe-lhe uma condição de inferioridade quando comparada ao gênero masculino ${ }^{(22)}$. Sem dúvida, esse será um empecilho para o enfrentamento da infecção por HIV e sua disseminação para futuras gerações.

Em contrapartida, a campanha realizada no Brasil busca sensibilizar para o uso do preservativo masculino, por meio das imagens. Destaca-se também que a proposta do governo brasileiro é direcionada tanto para casais heterossexuais quanto para homossexuais. Desse modo, as questões de gênero são abordadas de formas distintas.

Apesar das diferentes abordagens, as representações sociais justificam os apelos 
comportamentais das campanhas publicitárias, nos quais constrói-se, no sistema cognitivo, uma realidade que integra valores, contexto social, elementos afetivos, mentais e sociais, associando linguagem e comunicação ${ }^{(25)}$.

Portanto, as questões culturais interferem diretamente nas campanhas publicitárias, principalmente nas noções de prevenção e promoção da saúde. Assim, deve-se atentar para o fato de que a Aids não é uma doença de transmissão ocorrente apenas no período do carnaval e nem exclusiva de pessoas que praticam a infidelidade.

Este estudo apresenta limitações relacionadas ao número mínimo de vídeos que foram analisados. Embora não se tenha encontrado maior quantidade de material que atendesse aos critérios de inclusão e exclusão definidos, é de relevante importância que mais estudos possam analisar outros materiais acerca da temática nos países lusófonos, bem como cabe a esses países promover e divulgar ações de prevenção ao HIV/Aids que ultrapassem as barreiras das instituições de saúde.

\section{Considerações finais}

As campanhas de combate à Aids são um importante instrumento de coleta de dados em pesquisa qualitativa, entretanto existem limitações, como duração e questões éticas, que são de suma importância para a construção do estudo. Nesse contexto, a análise dos vídeos possibilitou maior entendimento acerca da epidemia da Aids/HIV e da forma como as instituições governamentais têm buscado sensibilizar a população recorrendo às mídias e propagandas publicitárias.

Quando se analisaram as diferentes visões da problemática, percebeu-se os inúmeros desafios a serem enfrentados no combate a essa enfermidade, que envolvem, dentre outras questões, representações sociais, questões de gênero e, principalmente, medidas de proteção. Campanhas publicitárias são importantes meios de transformação social, entretanto percebeu-se que inúmeras foram as diferenças entre as campanhas realizadas no Brasil e aquelas produzidas em Angola, principalmente relacionadas aos métodos de proteção e relações de gênero.

Embora se saiba que não é possível abordar todos os aspectos socioculturais em vídeos de no máximo 60 segundos, nota-se a necessidade de reformulação e divulgação dessas mídias em períodos constantes, não se restringido a épocas específicas do ano. Essas podem ser complementadas por meio de ações educativas em Unidades de Atenção Primária à Saúde, escolas e outros meios coletivos. Nesse quesito, as principais mudanças devem ser direcionadas para o enfrentamento e a mudança de atitude frente ao HIV, pela identificação de problemas relacionados aos meios de infecção e como as pessoas podem conviver com qualidade de vida frente ao processo crônico que é o HIV/Aids.

\section{Colaborações:}

1 - concepção, projeto, análise e interpretação dos dados: Isabelly Gomes de Oliveira, Antônio Uelton de Araújo da Silva e Márcio Flávio Moura de Araújo;

2 - redação do artigo e revisão crítica relevante do conteúdo intelectual: Isabelly Gomes de Oliveira, Lydia Vieira Freitas dos Santos, Antônio Uelton de Araújo da Silva, Márcio Flávio Moura de Araújo, Hévila Ferreira Gomes Medeiros Braga e Emanuella Silva Joventino Melo;

3 - aprovação final da versão a ser publicada: Lydia Vieira Freitas dos Santos e Emanuella Silva Joventino Melo.

\section{Referências}

1. Brasil. Ministério da Saúde. Secretaria de Vigilância em Saúde. Departamento de DST, Aids e hepatites virais. Cuidado integral às pessoas que vivem com HIV pela Atenção Básica: Manual para a equipe multiprofissional [Internet]. Brasília (DF); 2015 [cited 2020 Jun 14]. Available from: http://www. aids.gov.br/pt-br/pub/2016/cuidado-integralpessoas-que-vivem-com-hiv-pela-atencao-basica

2. Unaids Brasil. Estatísticas 2019 [Internet]. Brasília (DF); 2019 [cited 2020 Jun 12]. Available from: https://unaids.org.br/estatisticas/ 
3. Brasil. Ministério da Saúde. Secretaria de Vigilância em Saúde. Departamento de Doenças de Condições Crônicas e Infecções Sexualmente Transmissíveis (DCCI). Relatório de monitoramento clínico do HIV [Internet]. 2a ed. Brasilia (DF); 2019 [cited 2020 Jun 14]. Available from: http://www.aids.gov.br/pt-br/pub/2019/ relatorio-de-monitoramento-clinico-do-hiv-2019

4. Brasil. Ministério da Saúde. Secretaria de Atenção à Saúde. Departamento de DST, Aids e Hepatites Virais. Manual técnico para o diagnóstico da infecção pelo HIV em adultos e crianças [Internet]. $4 a$ ed. Brasília (DF); 2018 [cited 2020 Jun 15]. Available from: http://www.aids.gov.br/pt-br/ node $/ 57787$

5. Brasil. Ministério da Saúde. Secretaria de Vigilância em Saúde. Departamento de Vigilância, Prevenção e Controle das Infecções Sexualmente Transmissíveis, do HIV/Aids e das Hepatites Virais. Protocolo clínico e diretrizes terapêuticas para manejo da infecção pelo HIV em adultos [Internet]. Brasília (DF); 2018 [cited 2020 Jun 15]. Available from: http://www.aids.gov.br/pt-br/pub/2013/ protocolo-clinico-e-diretrizes-terapeuticas-paramanejo-da-infeccao-pelo-hiv-em-adultos

6. Endo ACB, Roque MAB. Atenção, memória e percepção: uma análise conceitual da Neuropsicologia aplicada à propaganda e sua influência no comportamento do consumidor. Intercom rev bras ciênc comun. 2017;40(1):77-96. DOI: http://dx.doi.org/10.1590/1809-5844201715

7. Lermen HS, Mora C, Neves ALM, Azize RL. Aids em cartazes: representações sobre sexualidade e prevenção da Aids nas campanhas de $1^{\circ}$ de dezembro no Brasil (2013-2017). Interface (Botucatu). 2020;24:e180626. DOI: https://doi. org/10.1590/Interface.180626

8. Pontes BS. Comunicação, AIDS e gênero: recepção de materiais educativos por usuárias gestantes de uma unidade da atenção básica no Rio de Janeiro [dissertação]. Rio de Janeiro: Fundação Oswaldo Cruz, Escola Nacional de Saúde Pública Sérgio Arouca; 2019.

9. Muñoz EE. A cooperação Sul-Sul do Brasil com a África. Cad CRH. 2016;29(76):9-12. DOI: http:// dx.doi.org/10.1590/S0103-49792016000100001

10. Global Digital Report. Digital Around the world in 2019. Digital: 2019 [Internet]. Nova York; 2019 [cited 2020 May 18]. Available from: https:// wearesocial.com/global-digital-report-2019
11. Dalmolin A, Girardon-Perlini NMO, Coppetti LC, Rossato GC, Gomes JS, Silva MEN. Vídeo educativo como recurso para educação em saúde a pessoas com colostomia e familiares. Rev gaúcha enferm. 2016;37:e68373. DOI: http://dx.doi. org/10.1590/1983-1447.2016.esp.68373

12. Bardin L. Análise de conteúdo. São Paulo: Martins Fontes; 2011.

13. Brasil. Ministério da Saúde. Secretaria de Atenção à Saúde. Saúde sexual e saúde reprodutiva. Caderno de Atenção Básica 26 [Internet]. Brasília (DF); 2013 [cited 2020 Jun 15]. Available from: http://bvsms.saude.gov.br/bvs/publicacoes/ saude_sexual_saude_reprodutiva.pdf

14. Moraes AAS, Suto CSS, Oliveira EM, Paiva MS, Ferreira CSB, Barreto MASA. O olhar de alunas de escola pública sobre o preservativo feminino. Rev gaúcha enferm. 2019; 40:e20180277. DOI: https://doi.org/10.1590/1983-1447.2019.20180277

15. Brasil. Ministério da Saúde. Secretaria de Vigilância em Saúde. Departamento de Vigilância, Prevenção e Controle das Infecções Sexualmente Transmissíveis, do HIV/Aids e das Hepatites Virais. Protocolo clínico e diretrizes terapêuticas para profilaxia pós-exposição (PEP) de risco à infecção pelo HIV, IST e hepatites virais [Internet]. Brasília (DF); 2018 [cited 2020 Jun 15]. Available from: http://www.aids.gov.br/pt-br/pub/2015/ protocolo-clinico-e-diretrizes-terapeuticas-paraprofilaxia-pos-exposicao-pep-de-risco

16. Garcia S, Berquó E, Lopes F, Lima LP, Souza FM. Práticas sexuais e vulnerabilidades ao HIV/aids no contexto brasileiro: considerações sobre as desigualdades de gênero, raça e geração no enfrentamento da epidemia. e-book Demografia em Debate [Internet]. 2015 [cited 2020 Jun 14];2(1):417-47. Available from: http://www.abep. org.br/ abeporgb/publicacoes/index.php/ebook/ article/viewFile/59/57

17. Fonte VRF, Pinheiro CDP, Barcelos NS, Costa CMA, Francisco MTR, Spindola T. Factores asociados con el uso del preservativo entre hombres jóvenes que tienen sexo con hombres. Enferm glob. 2017;16(2):50-93. DOI: https://doi.org/10.6018/ eglobal.16.2.245451

18. Barbosa KF, Batista AP, Nacife MBPSL, Vianna VN, Oliveira WW, Machado EL, et al. Fatores associados ao não uso de preservativo e prevalência de HIV, hepatites virais B e C e sífilis: estudo transversal em comunidades rurais de Ouro Preto, Minas Gerais, entre 2014 e 2016. 
Epidemiol serv saúde. 2019;28(2):e2018408. DOI: https://dx.doi.org/10.5123/s1679-4974201 9000200023

19. Lima AF, Andrada ACAC, Vieira IDHP, Silva RPNR, Paiva TF, Lucinda LMF, et al. Vulnerabilidade ao HIV/AIDS entre universitários de Barbacena-MG. Rev méd Minas Gerais. 2017;27(Suppl 1):66-72. DOI: http://www.dx.doi. org/10.5935/2238-3182.20170011

20. ONU News. Onusida destaca esforços para acabar com o HIV/Sida em Angola [Internet]. Nova York; 2016 [cited 2020 Jun 17]. Available from: https://news.un.org/pt/audio/2016/07/1178941

21. Howe CJ, Fuller CM, Ompad DC, Galea S, Koblin B, Thomas D, et al. Association of sex, hygiene and drug equipment sharing with hepatitis $C$ virus infection among non-injecting drug users in New York City. Drug Alcohol Depend. 2005;79(3):389-95. DOI: https://doi.org/10.1016/ j.drugalcdep.2005.03.004

22. Silva EA. Tradição e identidade de género em Angola: ser mulher no mundo rural. Rev Angolana de Sociologia [Internet]. 2011 [cited 2020 Jun 14];8:21-34. Available from: http://repositorium. sdum.uminho.pt/handle/1822/20538

23. DW Made for minds. Mediateca. Falta de vontade política para combater HIV/SIDA em Angola [Internet]. Berlim (DEU); 2019 [cited 2020 Jun 14]. Available from: https://www. dw.com/pt-002/falta-vontade-pol\%C3\%ADticapara-combater-hiv-sida-em-angola/ av-48712609

24. Silva TCF, Sousa LRM, Jesus GJ, Argolo JGM, Gir ERRK, Reis RK. Fatores associados ao uso consistente do preservativo masculino entre mulheres vivendo com HIV/AIDS. Texto contextoenferm. 2019;28:e20180124. DOI: https://doi. org/10.1590/1980-265x-tce-2018-0124

25. Moscovici S. A representação social da psicanálise. Rio de Janeiro: Zahar; 1978.

Recebido: 6 de agosto de 2020 Aprovado: 29 de setembro de 2020 Publicado: 1 de dezembro de 2020

A Revista Baiana de Enfermagem utiliza a Licença Creative Commons - Atribuição-NãoComercial 4.0 Internacional. https://creativecommons.org/licenses/by-nc/4.0/ Este artigo é de acesso aberto distribuído sob os termos da Licença Creative Commons (CC BY-NC). Esta licença permite que outros remixem, adaptem e criem a partir do seu trabalho para fins não comerciais. Embora os novos trabalhos tenham de lhe atribuir o devido crédito e não possam ser usados para fins comerciais, os usuários não têm de licenciar esses trabalhos derivados sob os mesmos termos. 